\title{
RESPONSABILIDADE SOCIAL EMPRESARIAL: UMA ANÁLISE BIBLIOMÉTRICA DA PRODUÇÃO CIENTÍFICA NO SÉCULO XXI
}

\author{
CORPORATE SOCIAL RESPONSIBILITY: A BIBLIOMETRIC \\ ANALYSIS OF SCIENTIFIC PRODUCTION IN THE 21ST CENTURY
}

\section{Thaiane de Almeida dos Passos}

Graduada em Administração pela Universidade Federal Rural do Rio de Janeiro (Nova Iguaçu/Brasil).

E-mail: thaiane.passos@outlook.com

\section{Marcio Silva Borges}

Doutor em Ciência Tecnologia e Inovação em Agropecuária pela Universidade Federal Rural do Rio de Janeiro (Seropédica/

Brasil). Professor na Universidade Federal Rural do Rio de Janeiro (Nova Iguaçu/Brasil).

E-mail: marcioborges@ufrrj.br 


\section{RESUMO}

O conceito de Responsabilidade Social Empresarial (RSE) surgiu no mundo na década de 1950 e no Brasil a partir dos anos 80. Parte do princípio de que as empresas têm responsabilidade direta sobre os impactos causados na sociedade e tem o dever de colaborar para que haja um desenvolvimento equilibrado. Este estudo teve como objetivo geral analisar a evolução da produção científica na área de Responsabilidade Social Empresarial, especificamente nas áreas de Ciências Sociais Aplicadas, presente na base de dados Scopus e produzir indicadores bibliométricos, bem como analisar a interdisciplinaridade da RSE entre outras áreas, no espaço temporal do ano 2000 até 2019. Através da pesquisa bibliográfica foi possivel observar uma grande mudança na concepção por parte dos indivíduos e organizações, em princípio o viés da RSE era visto apenas como filantropia, e as mudanças foram além do que a organização poderia ganhar com a inclusão da RSE. A pesquisa bibliométrica demonstrou a evolução dos estudos sobre a RSE no século XXI, onde foi observado um crescimento médio de 31\%, passou de 18 publicações no ano 2000 para 1.491 em 2019. Observou-se também que, ao analisar o impacto das publicações e as palavras-chave, $21 \%$ dos estudos mais citados tratam de assuntos relacionados à Teoria dos Stakeholders. De maneira geral, este estudo expôs o perfil macro da produção científica sobre RSE e que o tema estudado permanece em evolução e em processo de consolidação visto a quantidade de teorias existentes dentro da RSE.

Palavras-chave: Responsabilidade Social Empresarial. Análise Bibliométrica. Base SCOPUS.

\section{ABSTRACT}

The concept of Corporate Social Responsibility (CSR) emerged in the world in the 1950s and in Brazil from the 1980s onto the 1980s. It assumes that companies have direct responsibility for the impacts on society and have a duty to work together for balanced development. This study had as general objective to analyze the evolution of scientific production in the area of Corporate Social Responsibility, specifically in the areas of Applied Social Sciences, present in the Scopus database and produce bibliometric indicators, as well as to analyze the interdisciplinarity of CSR among other areas, in the time space from 2000 to 2019. Through bibliographical research it was possible to observe a great change in the conception by individuals and organizations, in principle the bias of CSR was seen only as philanthropy, the changes went beyond what the organization could gain from the inclusion of CSR. The bibliometric research demonstrated the evolution of studies on CSR in the 21st century, where an average growth of 31\% was observed, from 18 publications in 2000 to 1,491 in 2019, it was also observed that when analyzing the impact of publications and keywords, it was found that $21 \%$ of the most cited studies deal with issues related to Stakeholder Theory. In general, this study exposed the macro profile of scientific production on CSR, the theme studied remains evolving and in the process of consolidation given the number of theories existing within CSR.

Keywords: Corporate Social Responsibility. Bibliometric analysis. SCOPUS Base. 


\section{INTRODUÇÃO}

Nos anos 60, a bióloga Rachel Carson publicou o livro Primavera Silenciosa, onde alertava sobre os perigos do uso indiscriminado de pesticidas e inseticidas químicos sintéticos nos EUA e o quão danoso estava sendo para o meio ambiente (CARSON, 2010). Primavera Silenciosa foi um marco para o movimento ambientalista, a autora clamava não apenas o fim do uso dos pesticidas, mas a necessidade de uma nova filosofia para a ciência, logo havia a urgência de refletir sobre a relação entre homem e natureza. (CARSON, 2010). O livro trouxe a tona um enorme problema ambiental, fazendo com que temas como este se transformassem em interesse público, conseguindo alarmar e chamar a atenção da opinião pública para o meio ambiente.

A inquietação produzida pelos efeitos das precipitações nucleares, pelas advertências de Primavera Silenciosa e por uma série de desastres ambientais levou a uma mudança de pensamentos e comportamentos que resultaram em um novo ambientalismo, com objetivos e demandas bem definidos e consciente da dimensão política dos mesmos, ganhando força e chamando a atenção para as consequências devastadoras que um crescimento sem limites poderia causar, tornando-se a preocupação pública e transformando-se em uma verdadeira Revolução Ambientalista (FERREIRA, 2008, p. 22).

Após o marco de Primavera Silenciosa, aconteceram outros eventos registrados na história como: Clube de Roma em 1968, Greenpeace em 1971, Conferência de Estocolmo em 1972, Primeiro Partido Verde em 1983, Relatório Brundtland em 1987, Fórum Global das Ongs em 1992, Eco 92, Rio + 5 em 1997, Rio + 10 em 2002. (FERREIRA, 2008, p. 15) e a Rio + 20 em 2012.

As reuniões organizadas pela Organização das Nações Unidas - ONU, desencadearam uma maior preocupação com relação às questões ambientais. A primeira Conferência sobre o Meio Ambiente, cujo objetivo era conscientizar a sociedade, se destacou por trazer à tona as ações humanas que estavam degradando o planeta provocando uma série de destruições que poderiam comprometer as gerações futuras. O "Relatório Brundtland" defendia a distribuição das riquezas como maneira de desenvolvimento global entre as posições divergentes entre países ricos e pobres, e foi o primeiro documento onde se empregou o termo Desenvolvimento sustentável, que é aquele que busca atender as necessidades atuais, sem comprometer as gerações futuras (PIMENTA; NARDELLI, 2015).

A preocupação em suprir as necessidades atuais sem comprometer as gerações futuras, caracteriza o desenvolvimento sustentável, então é dever das organizações que utilizam os recursos naturais, utilizá- 
los de maneira sustentável, e essas questões são evidenciadas na pesquisa sobre Responsabilidade Social Empresarial - RSE proposta neste trabalho.

A ideia de Responsabilidade Social Empresarial, parte do princípio de que as empresas têm responsabilidade direta sobre muitos problemas que abalam a sociedade, e, com isso, têm condições e o dever de colaborar para que haja um desenvolvimento equilibrado. De acordo com essa premissa, as ações realizadas pelas empresas através de suas técnicas e recursos visando atingir seus objetivos materiais, podem também colaborar para resolução de problemas sociais (TOMEl, 1984).

Johnson (1971, p. 50) definiu:

\begin{abstract}
Uma empresa socialmente responsável é uma organização cuja administração faz um balanço entre os diversos interesses. Essa empresa leva em conta não somente 0 interesse em maximizar os lucros para os acionistas, mas também os interesses dos empregados, fornecedores, da comunidade local e da nação (apud CARROLL, 1999).
\end{abstract}

O movimento de Responsabilidade Social Empresarial (RSE), reuniu esforços políticos, através das políticas ambientais, com objetivo que as empresas estejam mais sintonizadas com as necessidades públicas e sociais, buscando a governança corporativa como um quadro para as organizações tratarem funcionários, consumidores e a comunidade de forma similar ao tratamento dado aos acionistas. Com o passar do tempo, se tornou fator preponderante para a atual sociedade, que faz com que exista uma maior expectativa por parte dos indivíduos quanto ao papel social a ser executado pelos empresários. O que torna as questões relacionadas a responsabilidade social, alvo de interesse por parte das organizações, devido ao seu impacto direto no valor econômico das empresas (PUPPIM, 2013).

Nos anos 90, o empresário Stephan Schmidheiny lançou o livro Mudando o Rumo (1992), onde demonstrava que o empresariado também poderia focalizar em sua estratégia de negócios nesse tipo de desenvolvimento, não privilegiando apenas o lado econômico, mas levando em conta também o meio ambiente.

Outro fator estudado, foi a imagem corporativa positiva, apontada por Spalenza e Amaral (2018) como sendo um benefício advindo de atividades sustentáveis, que não implicam diretamente no lucro. Hart (1995) aponta para a atividade voluntária como a principal beneficiadora da imagem, em que a organização passa a ser vista pela sociedade e clientes como socialmente responsável.

A conjuntura mundial é marcada por grandes mudanças no que tange a sustentabilidade do planeta, onde se torna irrefutável a necessidade de que haja uma consciência empresarial. As incessantes mudanças impostas pela sociedade exigem atitudes por parte das organizações e seus gestores, sejam elas públicas ou privadas, passam a serem cobradas pelos impactos causados por suas atividades ao 
meio ambiente. Partindo deste princípio, os empresários e gestores foram obrigados a se adequarem para diminuir os impactos decorrentes de seus negócios. Logo, identifica-se uma urgência de que as organizações conduzam seus processos emparelhados aos constantes avanços tecnológicos e inovações, a fim de agregar práticas de responsabilidade, às práticas de gestão tradicional.

De um lado, a crescente preocupação ambiental, e de outro, as organizações adotando novas estratégias que estimulem o crescimento financeiro, ao mesmo tempo em queassumemaresponsabilidade social referente a sua atividade. É notório que existe uma evolução nos estudos Responsabilidade Social Empresarial (RSE), devido ao seu impacto em toda a sociedade, mas como essa evolução está acontecendo?

Este estudo teve como objetivo geral analisar a evolução da produção científica na área de Responsabilidade Social Empresarial, especificamente nas áreas de Ciências Sociais Aplicadas, presente na base de dados Scopus, e produzir indicadores bibliométricos, bem como analisar a interdisciplinaridade da RSE entre outras áreas, no espaço temporal do ano 2000 até 2019. A partir do objetivo geral, identificar quanto a comunidade acadêmica está contribuindo através de pesquisas e trabalhos, quais são os países e instituiç̧ões em que mais publicaram sobre a RSE e quais autores são mais citados. Para responder essas questões o presente trabalho está baseado na seguinte problemática: A evolução da produção científica sobre a Responsabilidade Social Empresarial, a partir do século XXI, seria uma percepção por parte do mundo empresarial que suas estratégias, a relação com a comunidade e com o meio ambiente precisam ser revistas?

A realização de pesquisas que busquem avaliar a produção científica, justifica-se conforme FERREIRA (1990), dada a relevância em mensurar a produção científica, identificando a bibliografia presente nas bases de dados, elencando temas em que exista uma produção considerável, possibilitando um exame para que identifique as principais perspectivas dentro da área a ser estudada e, consequentemente, elevando a troca de informações entre a comunidade acadêmica.

A atual crise mundial trouxe à tona a emergência de se estimular modificações nos modelos de gestão tradicionais. A crise econômica abala demasiadamente todos os setores da economia e vivenciamos hoje uma crise ecológica devido a rápida mudança da conjuntura climática, devido ao uso exagerado dos recursos naturais e o aquecimento global. A prática do capitalismo vem trazendo grandes impactos, formando uma sociedade cada vez mais voltada para o consumo, além de trazer problemas a precarização do trabalho (BOFF, 2014). Como avalia Boff (2014) "Estamos diante de uma grave crise civilizatória".

Pelas palavras da Carta da Terra, a sustentabilidade é questão crucial para a permanência da vida na terra, nunca a sociedade correu tanto risco que ameaçasse o futuro de todos. O que não se pode é, por descuido e ignorância, chegar tarde demais. Mais vale o princípio da precaução e da prevenção do que o 
da indiferença, o ideal é que a população dê a devida importância para que cheguemos a um estágio de sustentabilidade geral, que proporcionará o alivio e a esperança para se construir mais história de um futuro promissor (BOFF, 2014).

As empresas causam um maior impacto devido as suas atividades, por isso há a necessidade de que estas sigam as normas e leis existentes, a fim de minimizar a degradação. A partir disso, constata-se a importância do estudo da RSE, pois apesar das leis e normas contribuírem para uma maior preservação é importante que esses valores estejam enraizados na cultura organizacional (PONCHIROLLI, 2009; SOUZA; SAMPAIO, 2006).

Os princípios da sustentabilidade exigem grandes mudanças na forma na qual os indivíduos agem, fazendo com que o atual modelo econômico voltado mais para a exploração do que para a preservação, seja substituído por um modelo mais sustentável em que haja um equilíbrio entre as partes (SOUZA; SAMPAIO, 2006).

Devido ao poder econômico das organizações, que em alguns casos é maior do que alguns países, na qual geram impacto local, nacional e global. Suas decisões vão além dos impactos econômicos, mas também em níveis sociais, ambientais e políticos (PUPPIM, 2013). Nesta vertente, percebe-se a importância em acompanhar e entender como está ocorrendo e evoluindo os estudos que alicercem a área da sustentabilidade, mais diretamente a RSE, para que seja possível questionar o status quo, contribuindo para o desenvolvimento sustentável.

\section{FUNDAMENTAÇÃO TEÓRICA}

Nos últimos anos, a forma que as empresas agem perante a sociedade tem sido foco de debates sociais e os estudos sobre o tema vem ascendendo em todo mundo, porém se desenvolvendo de maneira heterogênea. Dissertar sobre responsabilidade social é discutir sobre um tema que está em foco no ambiente corporativo e na sociedade.

O conceito de responsabilidade social empresarial traz consigo uma diversidade de construtos, apresentando um cenário de teorias com a disseminação de diversas abordagens (YEVDOKIMOVA et al., 2018). Os primeiros indícios sobre RSE são datados a partir de 1920, ano em que surgiu o termo "filantropia de risco" que envolvia as ações realizadas individualmente por parte dos empresários e não ligadas diretamente às empresas. Entretanto em 1889, Andrew Carnegie empresário e filantropo, publicou o livro "The Gospel of Wealth", onde argumentava que a vida de um empresário bem sucedido, deveria envolver duas partes a "primeira dedicada à coleta e acumulação de riqueza e a segunda à distribuição subsequente dessa riqueza para causas nobres" (YEVDOKIMOVA et al., 2018, p. 70). 
No entanto, foi na década de 1950 que a Responsabilidade Social Empresarial começou a ser discutida de maneira especifica, a partir dos estudos do economista Howard Bowen, no livro Social Responsibilities of the Businessman, que definiu a RSE, chamada inicialmente de Responsabilidade Social (RS), como "referese às obrigações dos empresários de seguir essas políticas, tomar essas decisões ou seguir as linhas de ação desejáveis em termos dos objetivos e valores da nossa sociedade" (BOWEN, 1953, p. 6). De acordo com Bowen (1953), a RS não seria uma solução para todos os problemas da sociedade, porém contribuiria de forma a guiar os negócios do futuro.

De acordo com Carrol (1999), as ideias da obra de Bowen já indicavam que as ações das organizações causariam impactos na vida da sociedade e que os empresários teriam uma responsabilidade muito mais ampla do que as cobertas pelas suas declarações de lucros e perdas. Em consonância, Puppim (2013) argumenta que esses impactos atingem diversos níveis econômicos. Os construtos de Bowen forneceram embasamento para a discursão sobre a teoria e prática das RSE na primeira metade do século XX.

A partir década de 1960, houve a expansão da literatura a respeito da RSE, surgiram diversas tentativas de formalizar de maneira mais precisa o que significaria a RSE. O escritor que mais se destacou nesta época foi Keith Davis, que definiu que as decisões tomadas e ações realizadas pelas organizações visavam objetivos além dos interesses econômicos e técnicos da empresa (CARROL, 1999).

William C. Frederick também ofereceu contribuições relevantes para a definição da RSE, argumentava que as empresas deveriam supervisionar suas ações, afim de que atendam as expectativas do público, proporcionando melhoria no bem estar socioeconômico, esta análise implicaria na visão de que os recursos naturais e humanos deveriam ser utilizados não visando a iniciativa privada, mas a sociedade no todo (FREDERICK, 1960).

Em 1963, Josesh W. McGuire declarou em seu livro Empresas e Sociedade, que as empresas não teriam apenas responsabilidade com as questões legais e econômicas, mas responsabilidades sociais, que vão além das obrigações impostas. McGuire trouxe uma definição de maneira mais objetiva englobando as questões econômicas e judiciais, expandiu sua definição alegando que as empresas devem se importar com questões políticas, pelo bem estar do local a qual está inserida, pela educação, pela saúde dos seus funcionários e pela sociedade no geral (CARROLL, 1999).

Na década de 1970, época que houve um agravamento da crise social e ambiental, foi o período de conscientização sobre a responsabilidade social, houve o aumento das discussões envolvendo o relacionamento entre as organizações, governo e sociedade, o conceito sobre RSE passou a ser visto em um contexto ético, envolvendo as diferentes necessidades dos atores sociais.

Conforme Carrol (1999), o mais importante não era o fato de as empresas estarem se tornando socialmente responsáveis, mas que estavam agindo em resposta ao ambiente social. 
Em 1976, Fitch (1976, p. 38) definiu a RSE, como a "tentativa de resolver problemas sociais causados total ou parcialmente pela corporação". Conforme Fitch (1976), uma empresa era considerada socialmente responsável quando fosse capaz de identificar os problemas sociais, buscar soluções plausiveis e saber quando entrar em ação para resolvê-los.

De acordo com o modelo de Carrol (1979), entende-se que as empresas são unidades econômicas fundamentais para a sociedade, logo espera-se que elas produzam serviços e obtenham seus lucros e da mesma forma que espera-se que as empresas gerem lucros, a sociedade também espera que as empresas ajam conforme a lei.

As responsabilidades econômicas e legais configuram responsabilidades obrigatórias para as organizações. A responsabilidade ética e discricionária (voluntária), definiu que essas responsabilidades vão além do que é esperado pelas empresas. A responsabilidade ética configura atitudes além das reposnsabilidades legais e as discricionárias que são caracterizadas como ações filantrópicas (CARROLL, 1999).

A conceituação de Carrol (1999) demonstrou um avanço importante na pesquisa sobre RSE, determinando diferentes dimensões sobre a Responsabilidade Social e descrevendo as responsabilidades que os gerentes devem cumprir.

No final da década de 1970, a empresa passa a ser vista como um orgão moral e as decisões organizacionais vão além do que era exigido por lei, e passam a ser percebidas como resultado do modelo planejado com seus objetivos, regras e procedimentos. Ocorre a substituição da pensamento individualista para o organizacional. Dessa forma, a noção de responsabilidade é separada do conceito de filantropia e começa a ligar-se às consequências e passa a referir-se consequências das atividades da empresa.

A partir dos anos 1980, com a volta do modelo liberal o conceito de RSE, passou por algumas mudanças, onde o mercado era fator de maior preponderância (MACÊDO, 2013). Surgiram temas alternativos dentro da RSE que também foram foco das discussões como desempenho social corporativo, políticas públicas, ética organizacional e teoria dos Stakeholders. Em 1987, Epstein (1987), relacionou a RSE aos conceitos de responsabilidade social, capacidade de resposta e a ética dos negócios.

Responsabilidade social corporativa relaciona-se principalmente à obtenção de resultados de decisões organizacionais relativas às questões ou problemas específicos que (por algum padrão normativo) têm efeitos benéficos, e não adversos, - efeitos sobre as partes interessadas corporativas pertinentes. A correção normativa dos produtos da ação corporativa tem sido o foco principal da responsabilidade social corporativa (EPSTEIN, 1987, p. 104). 
Neste mesmo periodo, Epstein (1987) também definiu o conceito de ética nos negócios e responsividade corporativa, que chamou de "processo de politica social civil", e argumentou que o ponto de partida para esse processo é a institucionalização desses fatores dentro das organizações.

Nos anos 1980, também eplodiram pesquisas que buscavam vincular o desempenho financeiro a RSE, tema que foi melhor discutido na decada seguinte, por Waddock e Graves (1997), indicando a RSE como causa de melhora nos resultados financeiros (SURROCA; TRIBO; WADDOCK, 2009).

Devido à congectura construída no decorrer da década de 1980, alguns autores procuram desenvolver modelos com objetivo de acompanhar a evolução da RSE, um dos principais modelos desenvolvidos na época foi o criado por Wartick e Cochan (1985), intitulado modelo de desempenho social corporativo, que utilizou "princípios, processos e políticas para integrar responsabilidade, responsividade e outros temas sociais a uma gestão administrativa." (MACÊDO, 2013).

Na década de 1980 surgiram duas abordagens que vinculavam a RSE à gestão estratégica: business \& society e social issues management. A linha de estudos intitulada Business \& Society, foca nos interesses dos atores sociais, no qual a empresa interage. Tal abordagem coloca a sociedade em primeiro lugar e a RSE consiste na relação entre as empresas e a sociedade. Diferente do que acontecia nos primeiros estudos da RSE, onde as ações realizadas pelas empresas eram vistas como filantropia (FARIA; SAUERBRONN, 2008).

A teoria dos Stakeholders considera que os grupos em que os agentes de interesse exercem influência nas ações a serem realizadas pela empresa, portanto, a essência da teoria está na democratização da ligação entre as empresas e a sociedade (PUPPIM, 2013).

Outra linha de estudos originada no mesmo período da Business \& Society, foi a abordagem representada pela escola de Social Issues Management, cujo objetivo era a criação de ferramentas de gestão que conseguissem aprimorar o desempenho e ético nas empresas, o foco está no aproveitamento de recursos e minimização de riscos (FARIA; SAUERBRONN, 2008).

Os anos 1990 ficaram marcados por reforçar as teorias desenvolvidas até a época, diferente das décadas anteriores não se criou novas definições, mas concentrou-se na elucidação das teorias propostas anteriormente enriquecendo o corpo da literatura sobre RSE e recebeu forte estímulo por meio da ação de entidades não governamentais, institutos de pesquisa e empresas que começaram a trabalhar com a questão. Neste período conforme Wood (1991), os temas cidadania corporativa, desempenho social corporativo e rentabilidade foram investigados com maior veemência.

É perceptível que a evolução verificada no tema de RSE está diretamente relacionada a mudança de valores imputada em decorrência do que o país atravessou: "de uma sociedade industrial, em que a 
RSE assume conotação econômica, para uma sociedade pós-industrial, onde o tema valoriza aspectos relacionados à melhora da qualidade de vida" (MACÊDO, 2013, p. 6).

De acordo com Jamali (2008), a RSE é integrada ao modelo de negócios, e sua política funciona como um mecanismo de autorregulação, expandiu e estabeleceu um modelo de Desempenho Social Corporativo, baseado no modelo Tridimensional proposto por Carrol em 1979. O modelo criado por Wood constitui um grande avanço nos estudos da RSE.

Os estudos sobre RSE já concebidos, vem criando inúmeros conceitos, metodologias e estratégias para a empresa moderna, porém sua definição ainda se encontra em evolução no século XXI. É perceptivel que boa parte dos modelos atuais são caracterizados como continuidades ou revisão dos modelos anteriormente propostos, mas buscando integrá-los de maneira uniforme para serem aplicados nas organizações.

A partir do ano 2000, foram identificadas relações da RSE com outros temas, como ética empresarial, sustentabilidade, gestão dos stakeholders e cidadania corporativa. Conforme Macêdo (2013, p. 7):

Também pela mudança de valor e consciência que a sociedade passa a ter, o entendimento e relevância de temas sociais passam a ser maiores e, com isso, as empresas buscam uma melhor percepção da comunidade acerca de sua atuação social. Houve um aumento da relação entre estratégia, ética e responsabilidade social.

Um dos principais fatores que desencadearam as discursões sobre os conceitos de RSE está diretamente ligado às demandas de uma sociedade globalizada, onde o fator social impacta diretamente nas decisões organizacionais, devido a cada vez mais existir uma busca por uma maior transparência por parte das empresas (SILVA, et al., 2017).

De acordo com Sanches et al. (2017), no Brasil, a partir dos anos 60 e 70, com um maior fortalecimento no processo de industrialização, houve um maior comprometimento da sociedade em temas ambientais e sociais, provavelmente devido as grandes consequências geradas por poluição industrial, altos índices de contaminação do ar em áreas urbanas, o que prejudicou gravemente a população local.

Ainda Conforme Sanches et al. (2017, p. 64),

[...] podemos observar que seu processo legislativo ainda continua em andamento, sendo esta cada vez mais presente nos estados e municípios da federação através de programas, legislações e implementação de políticas que visam tratar do meio ambiente de uma forma mais adequada e criteriosa. 


\section{METODOLOGIA}

No ponto de vista metodológico este trabalho se caracteriza como pesquisa exploratória, bibliográfica, descritiva e bibliométrica, isto é, implicará na realização de pesquisa bibliográfica para propiciar um arcabouço teórico sobre o que vem sendo discutido sobre o tema, elemento que será importante para o desenvolvimento do referencial teórico; e descritiva pois se propõe observar, classificar, registrar, analisar e interpretar dados, sem que haja manipulação por parte do pesquisador através da pesquisa bibliométrica.

A técnica utilizada para a coleta de dados será a pesquisa bibliométrica, que é a parte focal deste trabalho, visto que, permitirá o alcance dos objetivos propostos. A pesquisa bibliométrica, se refere à técnica estatística que possibilita mensurar a produção científica, acompanhar o crescimento das áreas de conhecimento (COSTA; LOPES et al., 2012).

A utilização dos estudos bibliométricos tem como vantagem principal a padronização das informações através da estatística, o que facilita na mensuração e visualização dos dados obtidos. 0 estudo revela informações das produções científicas realizadas até o momento, trazendo os aspectos importantes já abordados e agregando conhecimento para a realização de novos trabalhos (MACHADO; BARBOSA; QUINTANA, 2011).

Normalmente, as pesquisas bibliométricas são desenvolvidas a partir das informações obtidas em grandes bases de dados como Web of Science, Scopus e mais recente Google Scholar Metrics. Cada base de dados possui suas características e particularidades, como público alvo, áreas temáticas de interesse e critérios de seleção, e envolvem uma série de dados, utilizando-se de diferentes métricas, tal qual devem ser utilizados de acordo com a área a ser estudada em consonante com os objetivos da pesquisa (COSTA; LOPES et al., 2012).

\subsection{COLETA E TRATAMENTO DOS DADOS}

Para se atingir os objetivos deste trabalho foi utilizada a base de dados Scopus, acessada através do Portal Capes, que permite que estudantes de instituições conveniadas tenham acesso gratuito às maiores plataformas de pesquisas.

A base Scopus trata-se de uma plataforma multidisciplinar que contém resumos de 27 milhões de artigos, referências, índices da literatura científica e indexa mais de 18.000 títulos de periódicos de 5.000 editoras internacionais, com atualizações diárias (COSTA; LOPES et al., 2012), oferece uma visão abrangente da produção de pesquisas do mundo nas áreas de ciência, tecnologia, medicina, ciências sociais e artes e humanidades (PRADO et al., 2017) e inclui mais idiomas para além do inglês, sendo 60\% da sua cobertura fora da América Anglo-saxônica (MESQUITA. R et al., 2006). 
O universo de investigação compreendeu todas as publicações indexadas na base Scopus no período de 2000 a 2019, para a coleta dos dados na página da Scopus, aplicou-se o seguinte conjunto de palavras: "corporate social responsibility" ou "environmental social responsibility" ou "social responsibility", em seguida foi aplicado o filtro "Business, Management and Accounting" e "Economics, Econometrics and Finance" para selecionar a área de pesquisa a ser analisada.

As categorias de análise estabelecidas, possuem as seguintes informações: evolução da produção científica, áreas de publicação, idiomas mais frequentes, distribuição geográfica das publicações, autores mais relevantes (Lei de Lotka), instituições com mais afiliados, periódicos que foram publicados (Lei de Bradford), palavras-chave (Lei de Zipf) e contagem de citações. Para análise e processamento dos dados da pesquisa, estas etapas foram operacionalizadas através dos filtros de pesquisa presentes na base Scopus e no Microsoft Excel.

\section{RESULTADOS E ANÁLISE}

A análise e discussão dos dados está pautada na investigação de artigos que constituem a amostra num recorte temporal de 2000 até 2019, e segue a seguinte ordem: i) evolução da produção científica, ii) Quantitativo por área de conhecimento, iii) Quantitativo por idioma, iv) Distribuição geográfica, v) Autores (Lei de Lotka), vi) Instituições com maior frequência de publicação, vii) Análise de periódicos (Lei de Bradford), viii) Fator de impacto de citações, ix) Análise das palavras-chave.

Foram encontrados 11.790 documentos no período de 2000 até 2019 sobre RSE na base Scopus. Percebeu-se que houve um crescimento médio de $31 \%$ no período analisado, tendo como destaque o ano de 2003 que registrou o maior percentual 174\%, e o único com variação negativa, ou seja, não houve um aumento superior em relação ao ano anterior, foi o ano de 2012, em que houve uma variação de -2\% em relação a 2011.

A tabela 1 demonstra quais foram as ocorrências encontradas ao analisar a quantidade de artigos publicados em cada ano de publicação. 


\begin{tabular}{|c|c|c|}
\hline Ano & Publicações & Variação (\%) \\
\hline 2000 & 18 & \\
\hline 2001 & 31 & $72 \%$ \\
\hline 2002 & 31 & $0 \%$ \\
\hline 2003 & 85 & $174 \%$ \\
\hline 2004 & 94 & $11 \%$ \\
\hline 2005 & 175 & $86 \%$ \\
\hline 2006 & 205 & $17 \%$ \\
\hline 2007 & 298 & $45 \%$ \\
\hline 2008 & 381 & $28 \%$ \\
\hline 2009 & 577 & $51 \%$ \\
\hline 2010 & 581 & $1 \%$ \\
\hline 2011 & 686 & $18 \%$ \\
\hline 2012 & 672 & $-2 \%$ \\
\hline 2013 & 752 & $12 \%$ \\
\hline 2014 & 916 & $22 \%$ \\
\hline 2015 & 929 & $1 \%$ \\
\hline 2016 & 1160 & $25 \%$ \\
\hline 2017 & 1232 & $6 \%$ \\
\hline 2018 & 1405 & $14 \%$ \\
\hline 2019 & 1491 & $6 \%$ \\
\hline
\end{tabular}

Fonte: Proponente da pesquisa

Na figura 1 é possível visualizar a evolução dos estudos sobre a RSE, em 2000 foram publicadas apenas 18 publicações por ano, em 2005 foram registrados 175, em 2010 foram registrados 581, alcançando 1.491 publicações no ano de 2019. 


\section{Gestãoe \\ Desenvolvimento}

Figura 1 - Evolução da produção científica sobre RSE

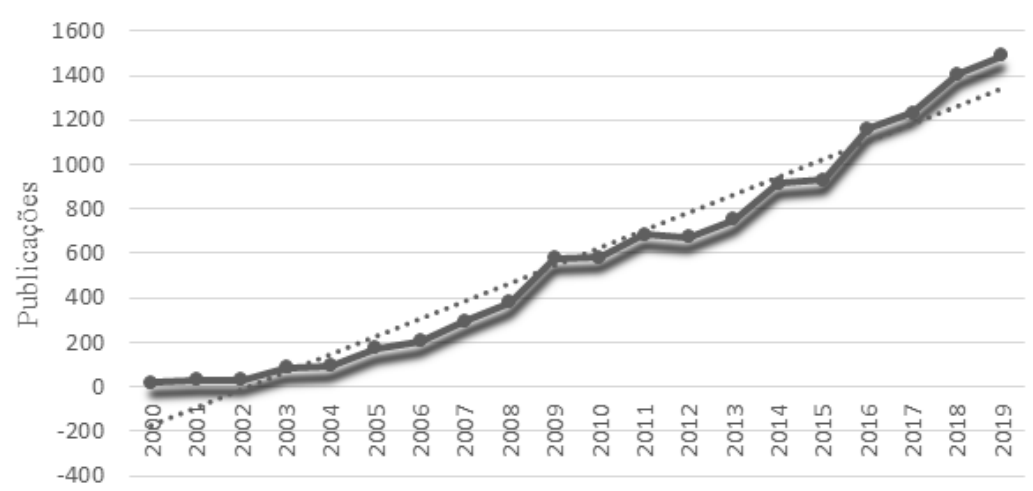

Fonte: Dados da pesquisa

De acordo com a tabela 2, do volume total de trabalhos publicados, as áreas de Ciências Sociais Aplicadas têm o maior percentual de publicações somando 60,3\% do total de publicações, sendo a área de Negócios, Administração e Contabilidade com 43.5\% e a área de Economia e Finanças com 20\%.

Tabela 2 - 15 áreas com maior número de publicações

\begin{tabular}{lll}
\hline Área & Publicações & Frequência (\%) \\
\hline Negócios, Administração e Contabilidade & 10667 & $43,5 \%$ \\
Economia e Finanças & 4903 & $20,0 \%$ \\
Ciências Sociais & 4150 & $16,9 \%$ \\
Artes e Humanidade & 1478 & $6,0 \%$ \\
Ciências Ambientais & 1003 & $4,1 \%$ \\
Ciências da decisão & 730 & $3,0 \%$ \\
Engenharia & 626 & $2,6 \%$ \\
\hline Energia & 353 & $1,4 \%$ \\
Ciências da computação & 199 & $0,8 \%$ \\
Psicologia & 170 & $0,7 \%$ \\
Agricultura e Ciências Biológicas & 115 & $0,5 \%$ \\
Medicina & 63 & $0,3 \%$ \\
Matemática & 40 & $0,2 \%$ \\
Ciências de materiais & 36 & $0,1 \%$ \\
Ciências da Terra e do Planeta & 16 & $0,1 \%$ \\
\hline
\end{tabular}

Fonte: Dados da pesquisa 
Cabe ressaltar o valor expressivo nas áreas de Ciências Sociais, devido ao impacto que a RSE tem na sociedade, conforme definição de Carrol (1979, p. 500), "A responsabilidade social dos negócios abrange as expectativas econômicas, legais, éticas e discricionárias que a sociedade tem das organizações em um determinado momento". Nas áreas de Artes e Humanidades, Ciências Ambientais e Ciências da Decisão, Engenharia e Energia o percentual varia de 6\% a 1,4\%, e em áreas como Ciências da Computação, Psicologia, Agricultura e Ciências Biológicas e, outras, demonstram menor relevância do tema nestas áreas.

Em relação a distribuição geográfica das publicações, registra-se que tal informação estava disponivel na base de dados apenas para 97,2\% da amostra. A figura 2 demostra o volume de produção científica por país. Observa-se que a maior proporção de produção (preto e cinza escuro) é oriunda dos Estados Unidos (17\%), Reino Unido (10,4\%), Espanha (5,4\%), Austrália $(5,2 \%)$, Canadá $(4,1 \%)$ e o menor volume de produção dentre os países que publicaram $0,1 \%$, entre eles têm-se por exemplo, Somália, Síria e Uzbequistão. Dentro da amostra pesquisada o Brasil apresentou 1,03\% das publicações da área.

Figura 2 - Produção científica sobre RSE por país

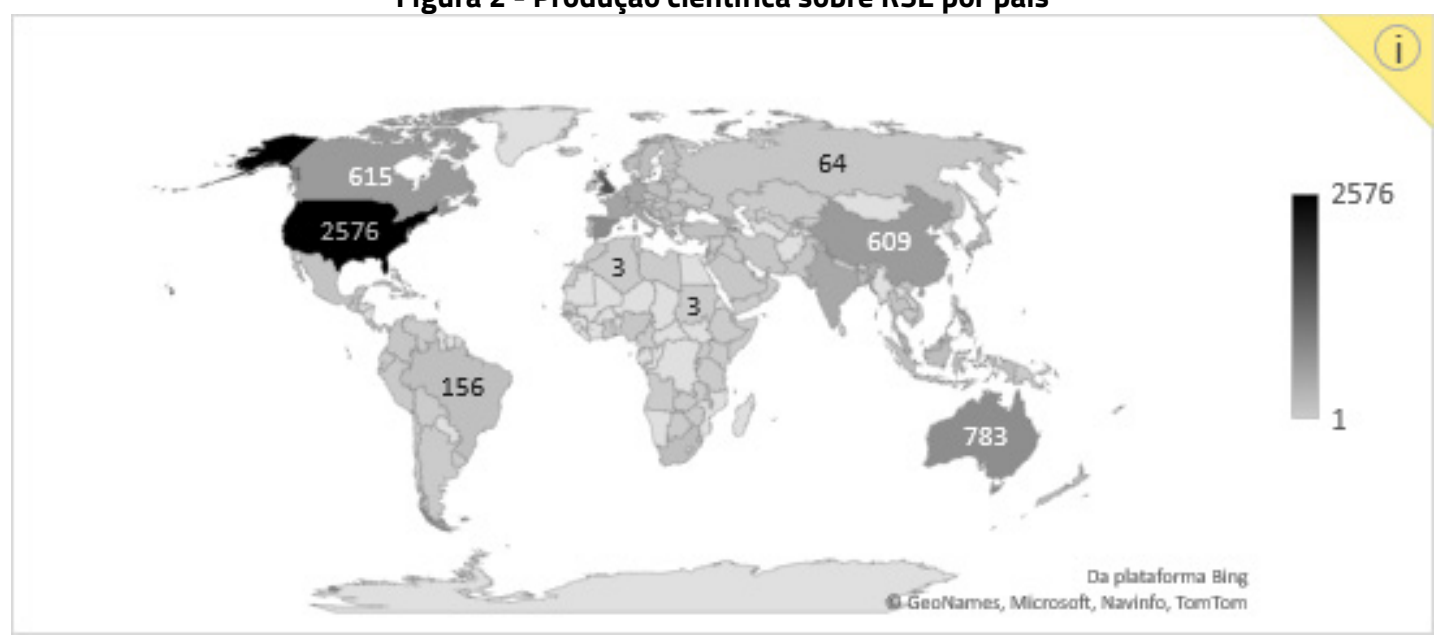

Fonte: Dados da pesquisa

Conforme a tabela 3, dos estudos publicados dentro da área de ciências sociais aplicadas, 96\% dos trabalhos foram publicados em inglês, seguido do espanhol com 1,8\%, francês com 0,5\% e 0,3\% em português. 
Tabela 3 - 15 idiomas com maior frequência de publicações

\begin{tabular}{lll}
\hline Idioma & Publicações & Frequência (\%) \\
\hline Inglês & 11398 & $96,5 \%$ \\
\hline Espanhol & 210 & $1,8 \%$ \\
\hline Francês & 56 & $0,5 \%$ \\
\hline Português & 30 & $0,3 \%$ \\
\hline Ucraniano & 27 & $0,2 \%$ \\
\hline Russo & 23 & $0,2 \%$ \\
\hline Polonês & 12 & $0,1 \%$ \\
\hline Alemão & 11 & $0,1 \%$ \\
\hline Romano & 9 & $0,1 \%$ \\
\hline Croata & 8 & $0,1 \%$ \\
\hline Lituano & 8 & $0,1 \%$ \\
\hline Chinês & 6 & $0,1 \%$ \\
\hline Japonês & 6 & $0,1 \%$ \\
\hline Italiano & 5 & $0,04 \%$ \\
\hline
\end{tabular}

Fonte: Dados da pesquisa

No que tange à mensuração da produtividade dos autores, a Lei de Lotka caracteriza a produção científica dos autores da seguinte maneira: poucos autores, produzem muito e muitos autores produzem pouco (GUEDES, BORSCHIVER, 2005). A figura 3 demonstra a quantidade de autores pela quantidade de artigos produzidos, o que confirma a teoria de Lotka, o formato de J invertido é adequado com o padrão de queda acentuada e tende a linearidade com uma extensa cauda de pequenos produtores. 
Figura 3 - Autores x Artigos produzidos

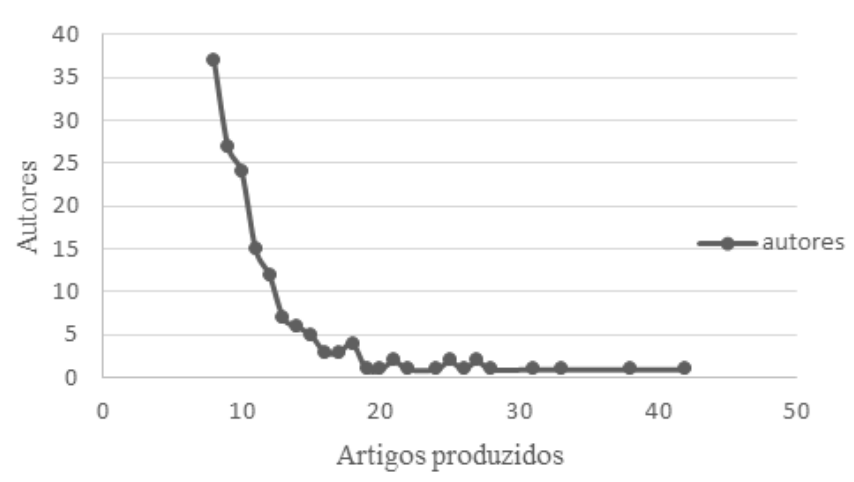

Fonte: Dados da pesquisa

Os autores que mais se destacaram em razão da sua produtividade são relacionados na tabela 4.

\begin{tabular}{ll} 
Tabela $\mathbf{4}$ - $\mathbf{1 0}$ autores com maior número de publicações \\
\hline Autor & Publicações \\
\hline Jamali, D. & 42 \\
\hline Lindgreen, A. & 38 \\
\hline García-Sánchez, I.M. & 33 \\
\hline Pérez, A. & 31 \\
\hline Martínez-Ferrero, J. & 28 \\
\hline Gond, J.P. & 27 \\
\hline Moon, J. & 27 \\
\hline Lee, S. & 26 \\
\hline Kolk, A. & 25 \\
\hline Swaen, V. & 25 \\
\hline
\end{tabular}

Fonte: Dados da pesquisa

No Brasil, as instituições que se destacaram com maior produtividade sobre o tema foram: Universidade de São Paulo com 24 publicações, Fundação Getúlio Vargas com 14 publicações, Universidade Federal do Rio de Janeiro e Universidade Federal do Ceará com 8 publicações.

Na tabela 5 constam as instituições com mais autores afiliados que publicaram pesquisas sobre a RSE. Conforme essa tabela, tiveram destaque as instituições: Copenhagen Business School com 130 afiliados, a York University com 96 afiliados, Universiteit van Amsterdam com 73, Bucharest University of Economic Studies e Nottingham University Business School ambas com 72 afiliados, com exceção da York 
University, todas as instituições estão situadas no continente Europeu, que indica que o continente Europeu é local que mais incentiva as pesquisas sobre RSE.

Na análise foram identificados 160 periódicos, a revista Journal Of Business Ethics publicou $36 \%$ das publicações sobre a RSE, Social Responsibility Journal 13\% e Corporate Social Responsibility And Environmental Management $11 \%$ das publicações. De acordo com a Lei de Bradford, a produção está dividida em três zonas, cada uma com 1/3 do total de publicações, para o caso aproximadamente 2.204 (6613/3) e em relação a quantidade de periódicos em cada zona, de acordo com a Lei a primeira zona possui Y, a $2^{\mathrm{a}}$ zona $3 Y$ e a $3^{\mathrm{a}}$ zona $3 Y^{2}$, aproximadamente 3, 9, 27.

Tabela 5 - 15 Instituições com maior número de publicações

\begin{tabular}{ll}
\hline Instituições & Afiliados \\
\hline Copenhagen Business School & 130 \\
\hline York University & 96 \\
\hline Universiteit van Amsterdam & 73 \\
\hline Bucharest University of Economic Studies & 72 \\
\hline Nottingham University Business School & 72 \\
\hline Universidad de Salamanca & 68 \\
\hline Deakin University & 66 \\
\hline Hong Kong Polytechnic University & 59 \\
\hline Universidad de Cantabria & 56 \\
\hline Erasmus Universiteit Rotterdam & 55 \\
\hline Curtin University & 55 \\
\hline University of South Australia & 55 \\
\hline Monash University & 54 \\
\hline American University of Beirut & 53 \\
\hline Griffith University & 52 \\
\hline \multicolumn{1}{|c|}{ Fonte: Dados da pesquisa } & \\
\hline
\end{tabular}

Fonte: Dados da pesquisa

A tabela 6 apresenta a comparação com os dados empíricos com o cálculo teórico. 


\section{Tabela 6 - Lei de Bradford comparação entre os dados teóricos e empíricos}

\begin{tabular}{|c|c|c|c|c|}
\hline \multirow[b]{2}{*}{ Zonas } & \multicolumn{2}{|l|}{ Cálculo Teórico } & \multicolumn{2}{|l|}{ Cálculo Empírico } \\
\hline & $\begin{array}{l}\text { Total de publica- } \\
\text { ções }\end{array}$ & $\begin{array}{l}N^{\circ} \text { de periódicos (multiplicador } \\
\text { de Bradford) }\end{array}$ & $\begin{array}{l}\text { Total de publica- } \\
\text { ções }\end{array}$ & $\begin{array}{l}N^{\circ} \text { de periódicos (multiplicador } \\
\text { de Bradford) }\end{array}$ \\
\hline Zona 1 & 2204 & 3 & 2204 & 4 \\
\hline Zona 2 & 4409 & 9 & 4409 & 6,5 \\
\hline Zona 3 & 6613 & 27 & 6613 & 5 \\
\hline
\end{tabular}

Fonte: Dados da pesquisa

Dos resultados obtidos, pode se observar que em nenhuma das zonas os resultados empíricos demonstraram conformidade com a Lei de Bradford, o que pode indicar que a área analisada em relação aos periódicos ainda está em processo de consolidação. A tabela 7 exibe os periódicos que compõe a primeira zona de Bradford.

Tabela 7- Periódicos na primeira zona de Bradford

\begin{tabular}{lll}
\hline Periódicos & Publicações & Frequência \\
\hline Journal Of Business Ethics & 1150 & $17,4 \%$ \\
Social Responsibility Journal & 428 & $6,5 \%$ \\
Corporate Social Responsibility and Environmental Management & 344 & $5,2 \%$ \\
Journal Of Cleaner Production & 227 & $3,4 \%$ \\
\hline
\end{tabular}

\section{Fonte: Dados da pesquisa}

Dentre os periódicos com maior percentual de publicação, Journal Of Business Ethics, Social Responsibility Journal, Corporate Social Responsibility And Environmental Management são pertencentes a área de Ciências Sociais Aplicadas, com exceção da Journal Of Cleaner Production que pertence a área de Ciências Ambientais.

Quanto ao impacto das publicações, a tabela 8 demonstra os 10 artigos com maior taxa de citações em valores absolutos e relativos, o valor absoluto contabiliza o total de citações, registrados desde 1996, e o valor relativo pondera-se o volume de citação em relação ao tempo de publicação. 
Tabela 8 - Fator de Impacto das Publicações

\begin{tabular}{|c|c|c|c|c|}
\hline Título da publicação & Autores & $\begin{array}{l}\text { Idade do } \\
\text { artigo }\end{array}$ & $\begin{array}{l}\text { Total de } \\
\text { Citações }\end{array}$ & $\begin{array}{l}\text { Citação } \\
\text { Relativa* }\end{array}$ \\
\hline $\begin{array}{l}\text { Strategy \&amp - Strategy and society: the link between com- } \\
\text { petitive advantage and corporate social responsibility }\end{array}$ & $\begin{array}{l}\text { Porter, ME. Kramer, } \\
\text { MR. }\end{array}$ & 14 & 3350 & 239,3 \\
\hline $\begin{array}{l}\text { Corporate social responsibility: A theory of the firm perspec- } \\
\text { tive }\end{array}$ & $\begin{array}{l}\text { McWilliams A., } \\
\text { Siegel D. }\end{array}$ & 19 & 2592 & 136,4 \\
\hline $\begin{array}{l}\text { Does doing good always lead to doing better? Consumer } \\
\text { reactions to corporate social responsibility }\end{array}$ & $\begin{array}{l}\text { Sen S., Bhattacha- } \\
\text { rya C.B. }\end{array}$ & 19 & 1825 & 96,1 \\
\hline $\begin{array}{l}\text { "Implicit" and "explicit" CSR: A conceptual framework for a } \\
\text { comparative understanding of corporate social responsibility }\end{array}$ & Matten D., Moon J. & 12 & 1612 & 134,3 \\
\hline $\begin{array}{l}\text { Why would corporations behave in socially responsible ways? } \\
\text { An institutional theory of corporate social responsibility }\end{array}$ & Campbell J.L. & 13 & 1565 & 120,4 \\
\hline $\begin{array}{l}\text { Corporate social responsibility and financial performance: } \\
\text { Correlation or misspecification? }\end{array}$ & $\begin{array}{l}\text { McWilliams A., } \\
\text { Siegel D. }\end{array}$ & 20 & 1386 & 69,3 \\
\hline Corporate social responsibility theories: Mapping the territory & Garriga E., Mele D. & 16 & 1376 & 86 \\
\hline $\begin{array}{l}\text { Putting the s back in corporate social responsibility: A multi- } \\
\text { level theory of social change in organizations }\end{array}$ & Aguilera R.V., et al & 12 & 1205 & 100,4 \\
\hline $\begin{array}{l}\text { How corporate social responsibility is defined: An analysis of } \\
37 \text { definitions }\end{array}$ & Dahlsrud A. & 12 & 1180 & 98,3 \\
\hline $\begin{array}{l}\text { Corporate social responsibility, customer Satisfaction, and } \\
\text { market value }\end{array}$ & $\begin{array}{l}\text { Luo X., Bhattacha- } \\
\text { rya C.B. }\end{array}$ & 13 & 1157 & 89 \\
\hline
\end{tabular}

\section{Fonte: Dados da pesquisa *Citação absoluta / idade do artigo.}

O volume de citação refere-se sobre a contribuição feita pelo trabalho à comunidade científica, no que tange a termos referência sobre o assunto, uma publicação é avaliada pelo número de vezes que a publicação foi citada em outros artigos (UMBELINO, 2008), o que indica que quanto maior for o número de obras que fazem referência ao trabalho, maior será o seu impacto na comunidade científica. Através dos trabalhos mais citados, é possível observar a relevância da teoria dos stakeholders na RSE, visto que 70\% dos trabalhos com maiores índices de citações estão relacionados a essa teoria.

No que tange aos assuntos de maior relevância dos trabalhos analisados, constatou-se a frequência de palavras-chave determinadas pelos autores, a tabela 9 apresenta a quantidade e o seu percentual relativo. As palavras quantificadas evidenciam a predominância de temas relacionados as partes 
interessadas, questões ambientais, estratégia e ética, visto que são as palavras com maiores números de ocorrências.

Tabela 9 - Frequência de palavras-chave

\begin{tabular}{lll}
\hline Palavras-chave & Quantidade & Frequência \% \\
\hline Stakeholder Theory, Stakeholder & 970 & $21 \%$ \\
\hline Sustainability & 735 & $16 \%$ \\
\hline Sustainable Development & 723 & $16 \%$ \\
\hline Corporate Governance & 474 & $10 \%$ \\
\hline Social Responsibility & 415 & $9 \%$ \\
\hline Economic And Social Effects & 372 & $8 \%$ \\
\hline Corporate Strategy & 301 & $7 \%$ \\
\hline Ethics & 298 & $7 \%$ \\
\hline Business Ethics & 285 & $6 \%$ \\
\hline
\end{tabular}

Fonte: Dados da pesquisa

\section{CONSIDERAÇÕES FINAIS}

No presente estudo, objetivou-se analisar a evolução da produção científica sobre Responsabilidade Social Empresarial na área de Ciências Sociais Aplicadas, indexados na base Scopus no espaço temporal de 2000 a 2019, bem como produzir indicadores bibliométricos e analisar a interdisciplinaridade da RSE com outras áreas do conhecimento, para responder a seguinte problemática: A evolução da produção científica sobre a Responsabilidade Social Empresarial, a partir do século XXI, seria uma percepção por parte do mundo empresarial de que suas estratégias, a relação com a comunidade e com o meio ambiente precisam ser revistas?

A pesquisa bibliométrica demostrou que a Responsabilidade Social Empresarial tem despertado o interesse de diversos autores ao redor do mundo, demonstrando ser um assunto relevante, dada a sua 
importância para a sociedade. Foi analisada a evolução dos estudos sobre a RSE no século XXI, onde foi observado um crescimento médio de 31\%, passando de 18 publicações no ano 2000 para 1.491 em 2019.

A pesquisa revelou que a maioria dos trabalhos são encontrados na área de Ciências Sociais Aplicadas com percentual de 60\%, porém nota-se que o tema também é bastante tratado nas áreas de Ciência Ambientais, Artes e Humanidade, representando 4,1\% e 6\% respectivamente.

Quanto à origem das publicações observou-se que 19\% das publicações são oriundas dos Estados Unidos, 11\% do Reino Unido, da Espanha e Austrália com 6\%, da China, França e Alemanha com 4\%, e 0 idioma mais frequente nas publicações é o inglês com percentual de $96,5 \%$, o que se deve aos países de origem, que, em sua maioria, possuem o inglês como língua nativa.

Em relação ao número de publicações por autor, os resultados da pesquisa estiveram em consonância com a Lei de Lotka, a qual afirma que poucos autores publicam muito e muitos autores publicam pouco. Foi constatado que $65 \%$ dos autores publicaram até 11 estudos e apenas 3\% publicam entre 31 a 42 estudos. Jamali, D. é o autor mais produtivo com 42 publicações, seguido por Lindgreen, A. com 38 publicações e García-Sánchez, I. M. com 33 publicações.

A pesquisa demostrou que as instituições com maiores índices de afiliados são a Copenhagen Business School, York University, Universiteit van Amsterdam e Bucharest University of Economic Studies. E os periódicos com maior quantidade de publicações foram Journal Of Business Ethics, Social Responsibility Journal e Corporate Social Responsibility And Environmental Management.

Cabe citar que as instituições brasileiras com mais afiliados são Universidade de São Paulo, Fundação Getúlio Vargas, Universidade Federal do Rio de Janeiro e Universidade Federal do Ceará.

Ao analisar o impacto das publicações e as palavras-chave, 21\% dos estudos mais citados tratam de assuntos relacionados à teoria dos stakeholders.

Ao analisar a amostra através da Lei de Bradford, quando comparados os dados teóricos aos dados empíricos, observou-se que as informações não se alinharam às diretrizes da lei de Bradford, isto é, pode indicar que os estudos sobre a RSE ainda não estão consolidados. O que também foi observado na pesquisa bibliográfica, visto que de acordo com Yevdokimova, Zamlynskyi et al. (2018), é que a RSE traz consigo uma diversidade de construtos, apresentando um cenário de teorias com a disseminação de diversas abordagens.

De maneira geral, este estudo expôs o perfil macro da produção científica sobre RSE, o tema estudado permanece em evolução e processo de consolidação visto a quantidade de teorias existentes inclusas. Mas espera-se que o trabalho venha contribuir no entendimento de como a produção do tema vem se desenvolvendo no século XXI. 
Observam-se que as informaç̃̃es apresentadas neste estudo podem estimular o desenvolvimento da produção científica sobre RSE. Visto que procurou-se contribuir para a disseminação, comunicação e propagação do tema, possibilitando o estímulo de produção de novos autores, contribuindo para a evolução da temática.

Este estudo limitou-se a analisar as publicações dentro da base de dados Scopus, no espaço temporal de 2000 a 2019, listados na área de Ciências Sociais Aplicadas. Diante disso, sugere-se para próximas pesquisas reproduzir o estudo utilizando outras bases de dados, realizando uma comparação entre os resultados, também se sugere uma pesquisa bibliométrica voltada para as publicações brasileiras para analisar o desenvolvimento do tema no Brasil.

Mesmo com as limitações apresentadas, cabe ressaltar que o desenvolvimento deste estudo se torna relevante, dado que, através da pesquisa bibliográfica, foi possivel observar a escassez de pesquisas bibliométricas sobre a RSE, que busquem analisar produção científica dentro da área de ciências sociais aplicadas.

Assim, o presente trabalho possibilitou, com a apresentação dos resultados, uma contribuição para que a sociedade se conscientize que a temática sobre RSE está posta, e que as organizações percebam, nessa evolução de publicações, uma importante oportunidade estratégica de se posicionar perante à sociedade e ao meio ambiente de maneira mais ética, eficaz e transparente.

\section{REFERÊNCIAS}

BOFF, L. Sustentabilidade o que é e o que não é. Petrópolis: Vozes, 2014.

BOWEN, H. Social Responsibilities of the Businessman. Nova lorque: Harper e Brothers, 1953.

CARROLL, A. B. Corporate Social Responsibility Evolution of a Definitional Construct. Business \& Society, Atlanta, v. 38, n. 3, p. 268-295, set. 1999.

CARSON, R. (1907 - 1964) Primavera Silenciosa. [Traduzido por Claudia Sant́Anna Martins]. 1. ed. São Paulo: Gaia, 2010.

COSTA LOPES, T. et al. A Bibliometria e a Avaliação da Produção Científica: indicadores e ferramentas. Lisboa, p. 7, 2012.

EPSTEIN, E. M. The corporate social policy process: Beyond business ethics, corporate social responsibility, and corporate social responsiveness. California Management Review, Berkeley, n. 29, p. 99-114, 1987. 
FARIA, A.; SAUERBRONN, F. F. A responsabilidade social é uma questão de estratégia? Uma abordagem critica. Revista de Administração Pública, Rio de Janeiro, v. 42, n. 1, p. 07-33, jan./fev. 2008.

FERREIRA, A. R. P. G. História do movimento ambientalista. 2008. 131 f. Dissertação (Mestrado em Desenvolvimento e Meio Ambiente) - Universidade Federal do Piauí, Teresina, Piauí, 2008.

FERREIRA, J. R. Produção científica em Educação Especial. In: DIAS, Tárcia Regina da Silveira; MENDES, Enicéia Gonçalves; DENARI, Fátima Elisabeth; REIS, Maria de Jesus Dutra dos; COSTA, Maria da Piedade Resende da. Temas em Educação Especial. 1. ed. São Carlos, SP: UFSCar. 1990. p. 97-99.

FITCH, H. G. Achieving corporate social responsibility. Academy of Management, Boston, v. 1, p. 38-46, 1976.

FREDERICK, W. C. The growing concern over business responsibility. Califórnia Management Review, Berkeley, v. 2, p. 54-61, 1960.

GUEDES, V. L.; BORSCHIVER, S. Bibliometria: Uma ferramenta estatística para a gestão da informação e do conhecimento em sistemas da informação, de comunicação de avaliação científica e tecnológica. Encontro Nacional de Ciência da Informação. 2005

HART, S. A natural-resource-based view of the firm. Academy of Management Review, v. 20, n. 4, p. 986-1014, oct. 1995.

JAMALI, D. A Stakeholder Approach to Corporate Social Responsibility: A Fresh Perspective into Theory and Practice. Journal of Business Ethics, Beirute, n. 82, p. 213-231, 2008.

MACÊDO, N. M. Considerações acerca da Responsabilidade Social Empresarial: um estudo a partir de sua evolução histórica. SEGeT Gestão da Tecnologia para a competitividade, 2013.

MACHADO, D. G.; BARBOSA, D. D. S.; QUINTANA, A. Análise da Produção Científica sobre os Fluxos de Caixa e a Demonstração dos Fluxos de Caixa: um estudo da Revista de Contabilidade e Finanças da Universidade de São Paulo, no período de 1989 a 2009. Enfoque: Reflexão Contábil, Maringá, v. 30, n. 2, 2011. Disponível em: http://www.periodicos.uem.br/ojs/index.php/Enfoque/article/view/12452. Acesso em: 13 nov. 2020.

MESQUITA, R. et al. Elaboração e aplicação de instrumentos para avaliação da base de dados Scopus. Perspectivas em Ciência da Informação, Belo Horizonte, v. 11, n. 2, maio/agosto 2006. Disponível em: http://portaldeperiodicos.eci.ufmg.br/index.php/pci/article/view/322. Acesso em: 24 abril. 2020. 
PIMENTA, M. F. F.; NARDELLI, A. M. B. Desenvolvimento sustentável: os avanços na discussão sobre os temas ambientais lançados pela conferência das Nações Unidas sobre o desenvolvimento sustentável, Rio+20 e os desafios para os próximos 20 anos. Perspectiva, Florianópolis, v. 33, n. 3, 12571252, set/dez 2015. Disponivel em: https://periodicos.ufsc.br/index.php/perspectiva/article/view/ 2175-795X.2015v33n3p1257. Acesso em: 10 out. 2020.

PONCHIROLLI, O. Ética e Responsabilidade Social Empresarial. 1. ed. Curitiba: Juruá, 2009.

PRADO, E. V. et al. Sistemas de Informações para Gerenciamento de Riscos Corporativos em Controladoria: Um Estudo Bibliométrico na Base de Dados Scopus. Perspectivas em Gestão \& Conhecimento, João Pessoa, v. 7, n. 1, p. 191-211, jan/jun 2017. Disponivel em: https://periodicos.ufpb.br/ojs2/index.php/ pgc/article/view/26824/17915. Acesso em: 14 out. 2020.

PUPPIM, J. A. Empresas na sociedade: sustentabilidade. RJ: Elsevier, 2013.

SILVA, et. al. Responsabilidade social corporativa na produção de cacau: análise das ações da indústria de chocolate. Revista Gestão e Desenvolvimento, Novo Hamburgo, v. 15, n. 1, jan./jun. 2018. Disponível em: https://periodicos.feevale.br/seer/index.php/revistagestaoedesenvolvimento/article/ view/1169/2125. Acesso em: 29 maio 2021.

SANCHES, et al. Descentralização da gestão ambiental no brasil: análise histórica dos principais momentos do processo. Revista Gestão e Desenvolvimento, Novo Hamburgo, v. 14, n. 2, jul./dez. 2017.

SOUZA, A. S. F. D.; SAMPAIO, C. A. C. In search of an ecodevelopment-oriented rationality: an exploratory study of sustainable tourism and entrepreneurial social responsibility projects. Revista de Administração Pública, Rio de Janeiro, v. 40, n. 3, p. 411-426, 2006. Disponível em: http://bibliotecadigital.fgv.br/ ojs/index.php/rap/article/view/6821. Acesso em: 25 out. 2006.

SPALENZA, A. S.; AMARAL, M. A. Estratégia Organizacional voltada para a lucratividade e sustentabilidade: um estudo de caso. Revista Gestão e Desenvolvimento, Novo Hamburgo, v. 15, n. 1, jan./jun. 2018. Disponivel em: https://periodicos.feevale.br/seer/index.php/revistagestaoedesenvolvimento/article/ view/1168/2123. Acesso em: 29 maio 2021.

SURROCA, J.; TRIBO, J. A.; WADDOCK, S. Corporate responsibility and financial performance: the role of intangible. Strategic Management Journal, v. 31, p. 463-490, setembro 2009 Disponivel em: https://onlinelibrary.wiley.com/doi/abs/10.1002/smj.820. Acesso em: 24 set. 2020.

TOMEI, P. A. Responsabilidade social de empresas: análise qualitativa da opinião do empresariado nacional. Revista de Administração de Empresas, Rio de Janeiro, v. 24, n. 4, p. 189-202, out/dez 1984. 


\section{Gestãoe \\ Desenvolvimento}

e-ISSN: 2446-6875

p-ISSN: 1807-5436

Disponivel em: https://rae.fgv.br/sites/rae.fgv.br/files/artigos/10.1590_S0034-75901984000400023. pdf. Acesso em: 05 out. 2020.

UMBELINO, F. M. B. C. Factor de impacto de Revistas Científicas na área de Enfermagem. Revista Referência, v. 2, p. 85-100, 2008. ISSN 8. Disponivel em: http://www.index-f.com/referencia/2008pdf/8-95100.pdf Acesso em: 20 jun. 2020.

WARTICK, S.; COCHRAN, P. The evolution of corporate social performance model. Academy of Management Review, v. 10, n. 4, p-758-769, 1985. Disponivel em: https://doi.org/10.5465/ amr.1985.4279099. Acesso em: 15 jul. 2020.

WOOD, D. Corporate social performance revisited. Academy of Management Review, vol. 16, n. 4, p. 691-718, 1991. Disponivel em: https://www.jstor.org/stable/258977?seq=1\#metadata_info_tab_contents. Acesso em: 15 jul. 2020.

YEVDOKIMOVA, M. et al. Evolution of corporate social responsibility applied to the concept of sustainable development. Journal Of Security And Sustainability ISSUES, v. 8, n. 3, p. 69-79, Março 2019. Disponível em: https://www.researchgate.net/publication/332003479_Evolution_of_corporate_social_responsibility_applied_to_the_concept_of_sustainable_development. Acesso em: 20 de ago. 2020. 